\title{
Pelaksanaan Pembagian Warisan Berdasarkan KUHPerdata Berkenaan Dengan Adanya Testamen
}

\author{
Agustina Suryaningtyas ${ }^{*}$
}

\section{Mahasiswa Program Magister (S2) Ilmu Hukum Fakultas Hukum UNISSULA Semarang, email :} suryastyas@gmail.com

\section{ABSTRAK}

Berbicara mengenai warisan, tidak terlepas dari suatu kematian seseorang. Warisan adalah harta peninggalan yang ditinggalkan pewaris kepada para ahli warisnya. Dalam hukum waris perdata terdapat 2 (dua) cara yang dapat digunakan untuk mendapatkan warisan, yaitu pewarisan menurut undang-undang (ab-intestato) dan pewarisan menurut surat wasiat (ad-testamento). Penelitian ini dilakukan dengan menggunakan metode yuridis normatif. Spesifikasi penelitian yang digunakan dalam penelitian ini adalah deskriptif analitis. Jenis data yang digunakan adalah data sekunder. Teknik analisis data yang digunakan dalam penelitian ini adalah analisis kualitatif yaitu cara analisis yang menghasilkan data-data deskriptif analitis, maksudnya apa yang di dapat responden secara tertulis dan lisan yang bersumber pada kenyataan di lapangan dikaitkan dengan data kepustakaan. Dari hasil penelitian, diketahui bahwa Pasal pertama Bab 13 menentukan bahwa segala harta yang ditinggalkan seseorang yang meninggal dunia adalah kepunyaan para ahli warisnya menurut undang-undang, sepanjang mengenai hal itu oleh pewaris tidak ditetapkan secara lain dengan sah. Artinya, Pasal 874 ini menentukan jika pewaris dengan sehelai surat wasiat menetapkan mengenai sebagian warisannya, maka sisa warisan dibagi menurut aturan pewarisan undang-undang. Dalam hal ini apabila isi testamen tersebut melanggar legiteme portie, ahli waris legitimaris dapat menuntut pembatalan testamen secara sederhana yaitu pembatalan bahwa ketetapan-ketetapan yang melanggar legitieme portie tidak dapat dijalankan.

Kata Kunci : Warisan, KUHPerdata, Testamen

\section{ABSTRACT}

Talking about the legacy, not apart from a person's death. Inheritance is the legacy left by the testator to his heirs. In the civil inheritance law there are two (2) ways that can be used to obtain the inheritance, that inheritance by law (ab-intestato), and inheritance according to the testament (adtestamento). This research was conducted using the method of normative. Specifications research used in this research is descriptive. The data used is secondary data. Data analysis techniques used in this research is the analysis of qualitative analysis method that produces descriptive data, which can mean anything the respondent in writing and orally were rooted in the reality on the ground is associated with literature data. From the research, it is known that the first article of Chapter 13 determines that all the treasures left behind someone who died belonged to the heirs according to law, all about it by the testator is not identified other legitimate. That is, Article 874 determines if the heir to a portion will set about his legacy, then the remaining estate is divided according to the rules of inheritance law. In this case if the contents testament of the will abuse legitieme portie, legitimaris heirs can demand cancellation testamentary simply that the cancellation of that provisions which violate legitieme portie can not be executed.

Keywords : legacy, Civil Code, Testamen.

\section{PENDAHULUAN}

Warisan dapat diartikan menyalurkan pikiran dan perhatian orang ke arah suatu kejadian penting dalam suatu masyarakat tertentu, ketika seorang anggota dari masyarakat itu meninggal 
dunia $^{1}$. Manusia dikenal sebagai makluk sosial, dimana dalam kebutuhannya, manusia tetap bergantung pada orang lain bahkan sampai pada saat dia meninggal. Terkadang seseorang jauh sebelum kematiannya, sering mempunyai maksud tertentu terhadap harta kekayaannya yang ditinggalkan, sehingga diperlukan suatu peraturan hukum yang mengatur, yaitu apa yang disebut hukum waris.

Hukum waris menurut Effendi Perangin : "Hukum Waris adalah hukum yang mengatur tentang bagaimana pembagian menurut undang-undang tentang harta kekayaan seseorang yang telah meninggal dunia dan yang mengatur dengan baik adanya suatu peristiwa hukum maupun perbuatan hukum dari harta kekayaan yang ditinggalkan oleh seseorang yang telah meninggal kepada ahli warisnya serta akibat-akibatnya bagi para ahli waris. ${ }^{2}$

Hukum waris yang ada dan berlaku di indonesia sendiri sampai saat ini masih terdapat pluralistik, akibatnya sampai sekarang ini pengaturan masalah waris di Indonesia masih belum terdapat keseragaman. Hukum waris yang berlaku di Indonesia antara lain Hukum Waris Adat, Hukum Waris Islam dan Hukum Waris berdasarkan KUHPerdata.

Secara umum dapat dikatakan bahwa hukum waris adalah hukum yang mengatur mengenai kedudukan harta dan kekayaan seseorang setelah meninggal dunia dan mengatur mengenai caracara berpindahnya harta kekayaan tersebut kepada orang lain.

Dalam hukum waris perdata terdapat 2 (dua) cara yang dapat digunakan untuk menerima warisan, yakni pewarisan menurut undang-undang (ab-intestato) dan pewarisan menurut surat wasiat (testamenter). ${ }^{3}$ Pewarisan ab-intestato dalam hukum waris merupakan pewarisan dimana ahli waris menerima warisan karena telah diatur dan diperintahkan oleh peraturan perundang-undangan yang berlaku. Ini berarti hak waris terhadap warisan didapatkan sesuai dengan ketentuan peraturan perundang-undangan yang berlaku.

Pewarisan testamenter dalam hukum waris undang-undang merupakan pewarisan yang dilakukan berdasarkan testamen atau biasa juga disebut dengan surat wasiat. Surat wasiat atau testamen ini biasanya berisi pernyataan.

Mengenai hal-hal yang diinginkan oleh pewaris terkait dengan warisan yang ditinggalkannya. Biasanya juga testamen ini dibuat di hadapan Notaris sehingga telah berisi keterangan yang jelas mengenai persentase atau jenis warisan yang ditinggalkannya kepada ahli waris yang dikehendakinya.

Berdasarkan latar belakang tersebut maka rumusan masalah dalam penelitian ini adalah : 1) Bagaimana pelaksanaan pembagian warisan berdasarkan KUHPerdata berkenaan dengan adanya testamen ? 2) Bagaimana konsekuensi hukum yang terjadi apabila testamen yang isinya melanggar hak-hak ahli waris yang berkedudukan sebagai legitimaris?

\section{Metode Penelitian}

Metode pendekatan dalam penelitian ini menggunakan metode yuridis normatif yaitu suatu penelitian yang secara deduktif dimulai analisa terhadap pasal-pasal dalam peraturan perundangundangan yang mengatur terhadap permasalahan diatas.

Spesifikasi penelitian yang digunakan dalam penelitian ini adalah deskriptif analitis. Artinya hasil penelitian ini berusaha memberikan gambaran secara menyeluruh, mendalam tentang suatu keadaan atau gejala yang di teliti. ${ }^{4}$ Deskriptif analitis menggambarkan peraturan yang sedang berlaku,

\footnotetext{
${ }^{1}$ Adrian Sutedi, 2009, Hukum Kepailitan, Ghalia, Bogor, hlm. 3.

2 Perangin Efendi, 2003, Hukum Waris, PT Raja Grafindo Persada, Jakarta, hlm. 3.

${ }^{3}$ R. Soetojo Prawirohamidjojo , 2000, Hukum Waris Kodifikasi, Airlangga University Press, Surabaya, hlm. 4.

${ }^{4}$ Soerjono Soekanto, 1986, Pengantar Penelitian Hukum, UI Press, Jakarta, hlm. 10
} 
yaitu KUHPerdata dikaitkan dengan teori-teori hukum dan praktek yang menyangkut obyek masalah yang diteliti, yaitu pihak-pihak terkait yang berperan dalam pembuatan surat wasiat atau testamen.

Jenis data yang digunakan dalam penelitian ini adalah : 1) Data Sekunder, yaitu data yang diperoleh melalui kepustakaan dengan jalan membaca, mengkaji serta mempelajari buku-buku relevan dengan obyek yang diteliti. ${ }^{5}$ Data sekunder dilakukan dengan penelitian kepustakaan yaitu mempelajari dan memahami literature-literatur ilmiah untuk mendapatkan landasan teoritis berupa pendapat-pendapat atau tulisan-tulisan para ahli dan pihak-pihak yang berwenang untuk memperoleh informasi baik dalam ketentuan formal ataupun naskah resume; 2) Teknik analisis data yang digunakan dalam penelitian ini adalah analisis kualitatif yaitu cara analisis yang menghasilkan data-data deskriptif analitis, maksudnya apa yang di dapat responden secara tertulis dan lisan yang bersumber pada kenyataan di lapangan dikaitkan dengan data kepustakaan.

Data-data yang telah berhasil dikumpulkan dalam penelitian (baik penelitian kepustakaan maupun penelitian lapangan) dilakukan editing kemudian dianalisa untuk selanjutnya disajikan dalam bentuk uraian.

\section{HASIL PENELITIAN DAN PEMBAHASAN}

\section{Pelaksanaan Pembagian Warisan berdasarkan KUHPerdata berkenaan dengan adanya Testamen.}

Legitieme Portie (atau wettelijk erfdeel, yang secara harfiah diterjemahkan sebagai "bagian warisan menurut undang-undang") di kalangan praktisi hukum sejak puluhan tahun dikenal sebagai "bagian mutlak". Bagian mutlak adalah bagian dari warisan yang diberikan oleh undang-undang kepada ahli waris dalam garis lurus ke atas dan ke bawah. Bagian itu tidak boleh ditetapkan secara lain oleh pewaris, baik secara hibah maupun dalam suatu surat wasiat. ${ }^{6}$

Dengan demikian pemegang hak mutlak (legitimaris) adalah keluarga pewaris dalam garis lurus. Istri atau suami bukanlah pemegang hak mutlak, walupun mereka ditetapkan dalam Hukum waris sebagai ahli waris dengan bagian yang sama besarnya dengan seorang anak sah, sebab mereka bukan ahli waris di garis lurus. Pewaris tidak berhak untuk menetapkan sesuatu tentang bagian mutlak ini dengan hibah atau dengan suatu ketentuan surat wasiat.

Bagian mutlak (legitieme portie) diberikan oleh undang-undang kepada masing-masing ahli waris dalam garis lurus, dan tidak kepada semua legitimaris bersama-sama. Dengan demikian masingmasing pemegang hak mutlak secara bebas berhak untuk melepaskan hak itu atau menuntutnya.

Walaupun pewaris tidak boleh membuat suatu penetapan (beschikking) atas bagian mutlak dan juga tidak boleh menetapkan ketentuan untuk mengaturnya, suatu penetapan wasiat yang melanggar bagian mutlak tidak batal demi undang-undang. Penetapan itu tetap berlaku, kecuali para legitimaris menuntut bagian mutlak bebas dari segala ketentuan.

Pewaris juga dilarang membuat suatu penetapan, bahwa bagian mutlak dikuasai oleh seorang pengurus khusus (bewindvoerder Pasal 1019 bagian akhir kalimat pertama). Larangan itu juga berlaku terhadap suatu ketetapan yang menentukan, umpamanya :

(1) Semua warisan berada dalam kekuasaan seorang pengurus khusus, kecuali bagian mutlak;

(2) Bagian mutlak tidak jatuh dalam harta bersama (gemeenschap van goederen)

\section{Konsekuensi Hukum yang terjadi apabila Testamen yang isinya melanggar hak-hak ahli waris yang berkedudukan sebagai Legitimaris.}

Dari uraian di atas, dapat disimpulkan, kemungkinan pembuatan testamen yang isinya ternyata

\footnotetext{
${ }^{5}$ Soerjono Soekanto dan Sri Pamudji, 1986, Penelitian Hukum Normatif,: CV. Rajawali , Jakart, hlm. 14

${ }^{6}$ Tang Thong Kie, 2007, Studi Notariat \& Serba-Serbi Praktek Notaris PT. Ichtiar Baru Van Hoeve, Jakarta, hlm.. 255
} 
melanggar legitieme portie, bisa saja terjadi. Dalam hal ini Notaris yang berkewajiban membuat dan menyimpan akta testamen, harus memberikan penjelasan dan nasehat yang diperlukan apabila terdapat hal-hal yang kurang tepat (dalam bidang hukum). Notaris tidak mempunyai wewenang untuk menentukan bagian waris, apabila dalam pembuatan terdapat pelanggaran legitieme portie, Notaris akan memberikan nasihat dan masukan hukum, namun apabila pewaris tetap pada pendiriannya, maka Notaris akan membuat testamen sesuai dengan kehendak pewaris.

Apabila dalam testamen tersebut terdapat pelanggaran legitieme portie, maka biarlah testamen itu berjalan apa adanya sesuai kehendak pewaris. Setelah testamen itu berjalan kemudian suatu saat ada pihak ahli waris legitimaris yang merasa dirugikan, barulah ahli waris dapat menuntut haknya.

Hal ini mengingat ketentuan tentang legitieme portie yang memang bersifat hukum memaksa, akan tetapi bukan demi kepentingan umum, melainkan untuk kepentingan legitimaris itu sendiri. Oleh karenanya legitimaris dapat membiarkan haknya dilanggar.

Pelanggaran tehadap legitieme portie tidak menyebabkan batal demi hukum, tetapi dapat diminta pembatalannya secara sederhana. Pembatalan secara sederhana bukan berarti seluruh ketentuan dalam testamen seluruhnya batal, akan tetapi hanya ketetapan-ketetapan yang terdapat dalam testamen dimana terdapat pelanggaran legitieme portie, tidak dapat dijalankan. Hal ini juga bukan berarti ahli waris berhak atas seluruh kekayaan pewaris, ia hanya dapat menuntut hak mutlaknya yang dilanggar. Setelah ketetapan-ketetapan dalam testamen tersebut dibatalkan, ahli waris mendapatkan bagian mutlaknya dengan cara melakukan pengurangan (inkorting).

\section{PENUTUP}

\section{Simpulan}

Berdasarkan hasil penelitian dan analisis data yang telah diuraikan dari Bab I sampai Bab IV diatas, maka dapat diambil kesimpulan :

1. Pelaksanaan pembagian warisan berdasarkan KUHPerdata berkenaan dengan adanya testamen rata-rata dilakukan oleh golongan Tionghoa, karena golongan ini tunduk pada KUHPerdata. Pelaksaan pembagian warisan melibatkan beberapa pihak antara lain :

a. Notaris, Peranan Notaris disini adalah membuat testamen sebagai alat bukti tertulis berdasarkan kehendak terakhir pewaris. Peranan Notaris dari awal hingga akhir pembuatan testamen sangat diperlukan, dari mulai pembuatan testamen, pendafaran testamen di Daftar Pusat Wasiat dan Balai Harta Peninggalan, serta pembukaan testamen apabila diketahui pewaris telah meninggal dunia. Pada prakteknya, testamen yang sering digunakan adalah testamen umum atau openbaar testamen, karena dengan testamen umum Notaris dapat mengawasi isi dalam testamen yang dibuatnya agar apa yang dikehendaki oleh pewaris tidak bertentangan dengan undang-undang.

b. Balai Harta Peninggalan, Peran Balai Harta Peninggalan dalam pembuatan surat wasiat ini adalah melaksanakan pembukaan surat wasiat tertutup / rahasia dan pendaftaran surat wasiat umum berdasarkan Pasal 937 dan Pasal 942KUHPerdata. Setelah si yang mewariskan meninggal dunia, maka surat tertutup atau rahasia tadi harus disampaikan kepada Balai Harta Peninggalan yang mana dalam daerahnya warisan yang bersangkutan telah jatuh meluang.

c. Daftar Pusat Wasiat, Seksi Daftar Pusat Wasiat mempunyai tugas melakukan penyusunan daftar wasiat atau testamen yang dilaporkan oleh Notaris baik testamen terbuka, testamen tertulis maupun testamen tertutup atau rahasia, serta meneliti daftar formal daftar wasiat dan penyiapan bahan penyelesaian permohonan surat keterangan wasiat.

Suatu testamen agar dapat berlaku sebagai akta otentik dan sah secara hukum harus memenuhi persyaratan yang telah ditetapkan oleh KUHPerdata, syarat tersebut terdiri syarat formil 
dan syarat materiil. Syarat formil meliputi dua hal yaitu berkenaan dengan subyek dan obyek testamen. Syarat materiil adalah syarat yang berkenaan dengan isi testamen.

2. Konsekuensi hukum yang terjadi apabila testamen yang isinya melanggar hak-hak ahli waris yang berkedudukan sebagai legitimaris, selama ahli waris legitimaris tidak menuntut hak nya, maka testamen itu akan berjalan sesuai dengan kehendak pewaris. Apabila ahli waris legitimaris merasa dirugikan atas pelanggaran terhadap hak nya, maka ahli waris legitimaris dapat menggugat pembatalan testamen secara sederhana. Pembatalan secara sederhana disini bukan berarti testamen tersebut batal secara keseluruhan, tetapi ketetapan-ketetapan yang terdapat dalam testamen yang melanggar bagian mutlak tidak dapat dijalankan. Setelah testamen dibatalkan secara sederhana ahli waris dapat menuntut bagiannya sesuai dengan porsi undang-undang.

\section{Saran}

Dari kesimpulan yang ada dan dari hasil penelitian yang sudah dilakasanakan, maka dapat dikemukakan beberapa saran :

1. Dalam pelaksanaan pembagian warisan, Notaris harus benar-benar memperhatikan keinginan dan kemampuan hukum dari si pembuat testamen dalam mengutarakan kehendaknya, yang kemudian akan dibuat dalam akta wasiat. Untuk menghindari ketidakberesan dalam pembuatan testamen, Notaris memberikan masukan dan saran hukum, Notaris hendaknya menjelaskan kepada pembuat testamen untuk mengutamakan bagian legitieme portie sebelum pembuatan testamen dilakukan.

2. Sebaiknya untuk mendapatkan hak-hak mutlak ahli waris legitimaris, maka ahli waris legitimaris hanya dapat menuntut bagian mutlaknya saja dan tidak menuntut agar harta peninggalan pewaris seluruhnya jatuh ke ahli waris legitimaris. Dengan demikian pengadilan tempat diajukan gugatan dapat benar-benar memerhatikan status hukum mereka sebagai ahli waris legitimaris yang sah dan berhak mewaris karena di dalam KUHPerdata melindungi anak-anak sah untuk berkedudukan sebagai ahliwaris, jika mereka mengajukan tuntutan untuk mendapatkan hak mutlak mereka terhadap harta peninggalan yang secara jelas dilindungi oleh undang-undang.

\section{DAFTAR PUSTAKA}

Adrian Sutedi, , 2009, Hukum Kepailitan, Ghalia, Bogor.

Prawirohamidjojo, R. Soetojo. Hukum Waris Kodifikasi, Airlangga Surabaya.

University Press, 2000.

Ali, Zainudin, 2008, Pelaksanaan Hukum Waris di Indonesia, Sinar, Jakarta

Amanat, Anisitus, 2001, Membagi Warisan Berdasarkan Pasal-Pasal Hukum Perdata BW, : PT Raja Grafindo Persada, Jakarta

Afandi, Ali, 1997 Hukum Waris, Hukum Keluarga, Hukum Pembuktian, PT. Rineka Cipta, Jakarta.

Mulyadi, 2011, Hukum Warisan Tanpa Wasiat, Badan Penerbit Universitas Diponegoro, Semarang.

Perangin, Effendi, 2005, Hukum Waris, Raja Grafindo Persada, Jakarta.

Prodjodikoro, Wirjono, 1980, Hukum Warisan di Indonesia, Sumur, Bandung.

Purnamasari, Irma Devita, 2014 Kiat-kiat Cerdas, Mudah dan Bijak Memahami Masalah Hukum Waris, Kaifa, Bandung

Satrio, J, 1990, Hukum Waris, Citra Aditya Bakti, Bandung. 
Jurnal Daulat Hukum Volume 1 No. 1 Maret 2018 : 265 - 270

Soekanto, Soerjono, 1986, Pengantar Penelitian Hukum, Universitas Indonesia Press, Jakarta

Soekanto, SoerjonoPamudji, Sri, 1986 Penelitian Hukum Normatif, CV. Rajawali, Jakarta

Soerjopratiknjo, Hartono. 1984, Hukum Waris Testamenter, Seksi Notariat Fakultas Hukum Universitas Gadjah Mada, Yogyakarta.

Sumitro, Ronny Hanintijo, 1984, Metodologi Penelitian Hukum, Ghalia Indonesia, Jakarta.

Tedjosaputro, Liliana, 1991, Hukum Waris Menurut KUHPerdata (Ab-Intestato), Agung Press, Semarang.

Sekretariat Negara Ri, Undang-Undang Dasar Negara Republik Indonesia Tahun 1945. Jakarta, 1945.

Sekretariat Negara RI, Kitab Undang-Undang Hukum Perdata (KUHPerdata).

Undang-Undang Nomor 2 Tahun 2014 tentang Perubahan Atas Undang-Undang Nomor 30 Tahun 2004 Tentang Jabatan Notaris. 